\title{
Brønsted Acid-catalyzed Addition and Cyclization Reaction with Imine: From Aqueous Reaction to Enantioselective Reactions
}

\author{
Takahiko Akiyama*, Kohei Fuchibe, and Junji Itoh \\ Department of Chemistry, Faculty of Science, Gakushuin University,
}

\section{Received June 30, 2005}

\begin{abstract}
Brønsted acid-catalyzed nucleophilic addition and cycloaddition reaction with imines are described. In the first part, $\mathrm{HBF}_{4}$-catalyzed Mannich-type reaction of silyl enolate with aldimine in aqueous media is described. When SDS was used as a surfactant, an organic solvent was not necessary and the carbon-carbon bond forming reactions proceeded smoothly in water alone as a solvent. Aza Diels-Alder reaction also took place in aqueous media by Brønsted acid catalysis. In the latter part, chiral Brønsted acidcatalyzed enantioselective reactions are presented. We prepared a cyclic phosphoric acid diester starting from $(R)$-BINOL. It was found that the acid exhibited excellent catalytic activity as a chiral Brønsted acid in the Mannich-type reaction, hydrophosphonylation, and aza Diels-Alder reaction.
\end{abstract}

\section{Introduction}

Numerous kinds of Lewis acid catalysts have been developed for carbon-carbon bond forming reactions. ${ }^{1}$ Transition metals as well as main group metals have been examined as central elements for the Lewis acid catalyst, wherein each element exerted unique character as a catalyst. Highly enantioselective reactions have been developed by means of a chiral Lewis acid catalyst. ${ }^{2}$ In contrast to their crucial role in synthetic organic chemistry, Brønsted acid catalysts have attracted less attention in carbon-carbon bond forming reactions until quite recently. ${ }^{3}$

Scheme 1. Lewis acid catalysis versus Brønsted acid catalysis

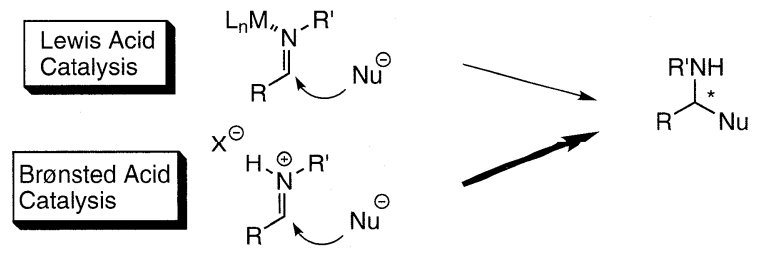

Advantages of Brønsted acid over Lewis acid follow;

(1) Lewis acids are generally sensitive toward water and oxygen, and hence, Lewis acid-catalyzed reactions are generally carried out under strictly anhydrous conditions. In contrast, Brønsted acids are usually stable towards water and oxygen. Brønsted acid-catalyzed reaction, thus, will be potentially viable in reactions in aqueous media and in air.

(2) With respect to chiral catalysts, chiral Lewis acid catalysts are generally prepared from Lewis acid and a chiral ligand in situ and used directly. Thus, chiral Lewis acids are generally not isolable. In contrast, chiral Brønsted acids are stable, isolable, and exhibit catalytic activity by themselves.

We have found Brønsted acid is a good activator of imines: Mannich-type reaction of silyl enolate to imine proceeded smoothly by means of $\mathrm{HBF}_{4}$ as a catalyst in an aqueous organic solvent to give a $\beta$-amino carbonyl compound in good yields. The $\mathrm{HBF}_{4}$-catalyzed Mannich-type reaction also took place in water in the presence of SDS as a surfactant. Aza Diels-Alder reaction also proceeded smoothly either in aqueous media or in water.

With the Brønsted acid-catalyzed carbon-carbon bond forming reactions in hand, we focused on chiral Brønsted acid-catalyzed enantioselective addition reaction toward imines. We have synthesized chiral phosphoric acid derivative 1, bearing a BINOL scaffold, and demonstrated its catalytic activity as a chiral catalyst. In the latter part of this account, chiral Brønsted acid-catalyzed enantioselective nucleophilic addition to imines will be described.

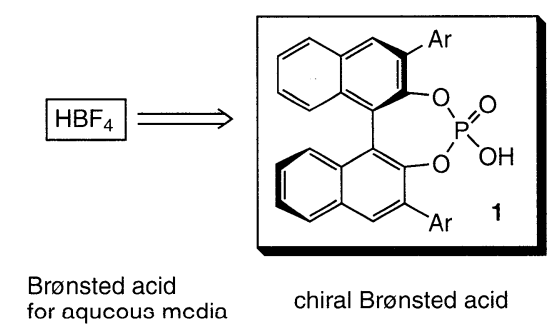

Figure 1

\section{Brønsted Acid Catalyzed Reactions in Aqueous Media}

Lewis acid-catalyzed carbon-carbon bond forming reactions are generally carried out under strictly anhydrous conditions because Lewis acids are sensitive to water. Because of the nature of the Brønsted acids, we expected that the Brønsted acids are viable under aqueous conditions. ${ }^{4}$ We focused on the carbon-nitrogen double bond as an electrophile. In contrast to nucleophilic addition reaction toward the carbonyl group, nucleophilic addition reaction toward imine has been less explored. The strong basicity of nitrogen may be responsible for the paucity of Lewis acid-catalyzed reactions because a stoichiometric amount of Lewis acid is required for the nucleophilic addition to imines.

\subsection{Brønsted Acid Catalyzed Mannich-type Reaction in Aqueous Media}

During our study on Lewis acid-catalyzed nucleophilic addition to imines, ${ }^{5}$ we examined the chemoselectivity between aldehyde and imine. It is generally believed that 
aldehydes are more reactive than imine. But Kobayashi and co-workers found that lanthanide triflate-mediated allylation and Mannich-type reactions proceeded smoothly toward aldimines in preference to aldehydes. ${ }^{6}$ Yamamoto and Nakamura reported similar selectivity by means of a $\mathrm{Pd}(\mathrm{II})$ catalyst. $^{7}$ We reinvestigated the chemoselectivity and found that addition of a protic species such as $\mathrm{H}_{2} \mathrm{O}$ or acetic acid suppressed the formation of the aldol product and $\beta$-amino ketone was obtained highly selectively (Table 1$){ }^{8}$

Table 1. Chemoselectivity between aldehyde and aldimine

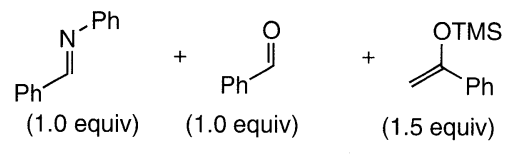

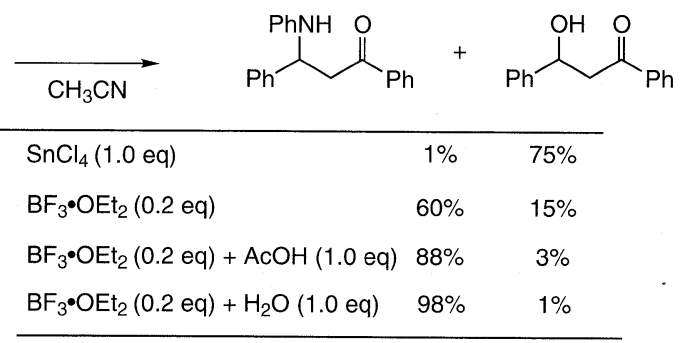

We surmised that the Mannich-type reaction was catalyzed by a Brønsted acid generated from $\mathrm{BF}_{3} \cdot \mathrm{OEt}_{2}$ and $\mathrm{H}_{2} \mathrm{O}{ }^{9}$ Hence we studied Brønsted acid catalyst for the Mannich-type reaction in aqueous media. Initial studies on the Brønsted acid in the Mannich-type reaction of $N$-benzylidene aniline and a silyl enol ether derived from acetophenone in aqueous organic solvent elucidated that $\mathrm{HBF}_{4}$ turned out to be the most effective and $\beta$-amino ketone was obtained in excellent yield (Scheme 2). $p$-TsOH was also effective, but $\mathrm{HF}$ and $\mathrm{HCl}$ were less effective.

Scheme 2. Effect of Brønsted acid in the Mannich-type reaction in aqueous solvent

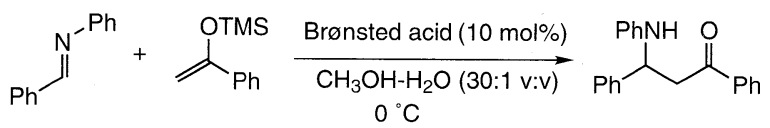

$\mathrm{HBF}_{4}: 96 \%, p-\mathrm{TsOH}: 89 \%, \mathrm{HPF}_{6}: 78 \%, \mathrm{HF}: 9 \%, \mathrm{HCl}: 6 \%$

It is noted that not only silyl enol ethers but also ketene silyl acetals, which are highly sensitive to moisture, do react smoothly in aqueous media. A range of aldimines derived from aromatic aldehyde and aniline underwent Mannich-type reaction with ketene silyl acetal as well as silyl enol ether under the influence of $\mathrm{HBF}_{4}(10 \mathrm{~mol} \%)$ in aqueous media to afford $\beta$-amino ketones and $\beta$-amino esters in high yields (Scheme 3). ${ }^{10}$ Aldimines derived from $\alpha, \beta$-unsaturated aldehyde gave exclusively the 1,2-adduct and formation of the 1,4-adduct was not observed. Use of aldimines derived from aniline derivatives is required for the present Mannich-type reactions to proceed. An aldimine derived from benzylamine did not give the adduct. Another characteristic feature of the present Mannich-type reaction is the excellent chemoselectivity toward aldimine in the presence of aldehyde. Aldol reaction did not proceed by means of $\mathrm{HBF}_{4}$. The high chemoselectivity is rationalized by the stronger basicity of nitrogen over oxygen.
Scheme 3. Mannich-type reaction in aqueous media

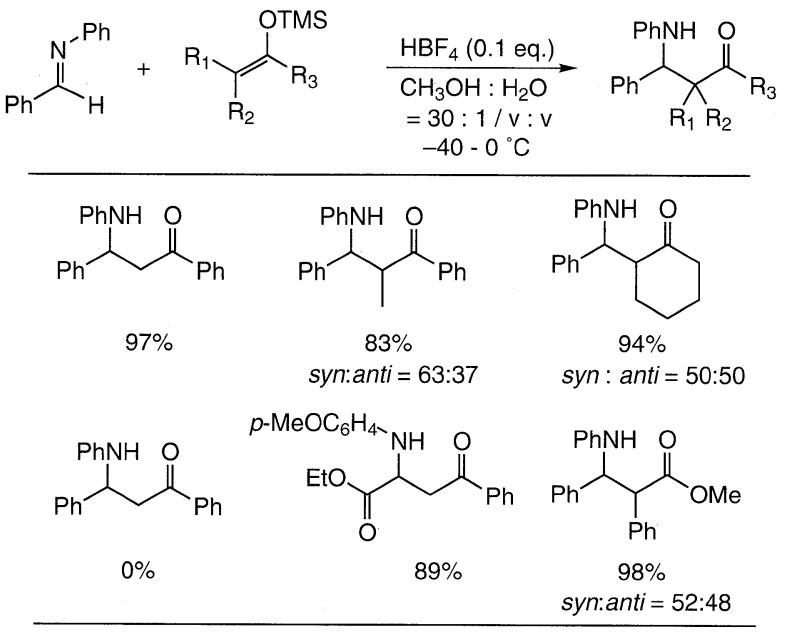

Since imines, in particular aliphatic aldimines, are not always stable and are difficult to purify, it would be synthetically quite useful if imines, generated in situ from aldehydes and amine, react with silyl enolates to afford $\beta$-amino carbonyl compounds in one vessel. Three-component synthesis starting from aldehyde, aniline, and silyl enolate proceeded

Scheme 4. Three-component Mannich-type reaction in aqueous media
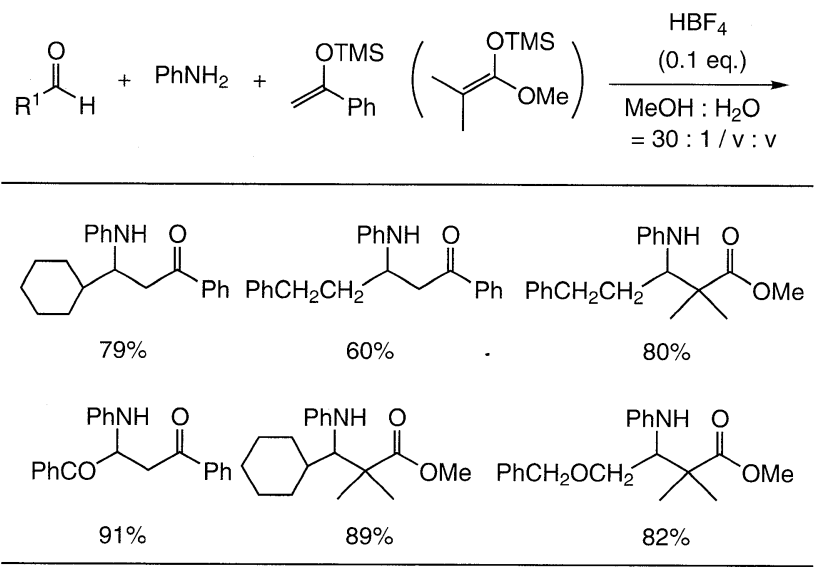

Scheme 5. Three-component Mannich-type reaction in water
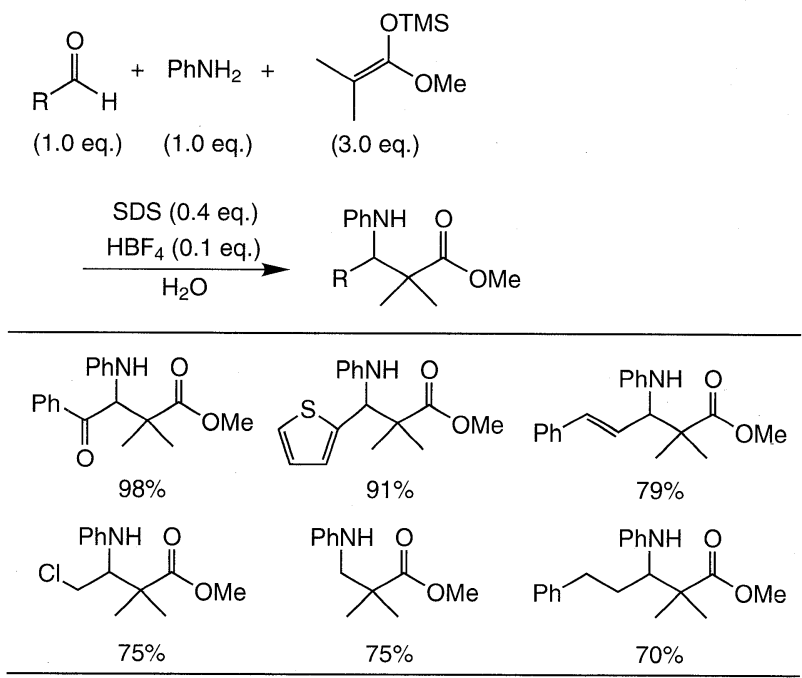
smoothly to afford $\beta$-carbonyl compounds in high yields (Scheme 4).

Furthermore, the Brønsted acid-catalyzed Mannich-type reaction was examined in water alone as a solvent. The Mannich-type reaction proceeded smoothly to afford $\beta$ amino ketones in good to high yields by addition of SDS (sodium dodecyl sulfate) as a surfactant. Ketene silyl acetals as well as silyl enol ethers were found to be viable nucleophiles in the present Mannich-type reaction. $\beta$-Amino esters were also obtained in high yields (Scheme 5). ${ }^{11}$

\subsection{Stereoselective Reactions ${ }^{12}$}

The $\mathrm{HBF}_{4}$-catalyzed Mannich-type reactions exhibited high diastereoselectivity by proper choice of the nucleophile and solvent systems. Thus, an treatment of aldimine with ketene silyl acetal 2a in the presence of $\mathrm{HBF}_{4}(10 \mathrm{~mol} \%)$ in SDS- $\mathrm{H}_{2} \mathrm{O}$, the syn adduct was obtained with good selectivity (Scheme 6). In contrast, use of ketene silyl acetal $\mathbf{2 b}$ in aqueous $i$-PrOH led to the exclusive formation of the ant $i$ adduct. It is noted that base-catalyzed ring-closing reaction furnished trans- $\beta$-lactam with high stereoselectivity.

Scheme 6. Syn-selective Mannich-type reaction

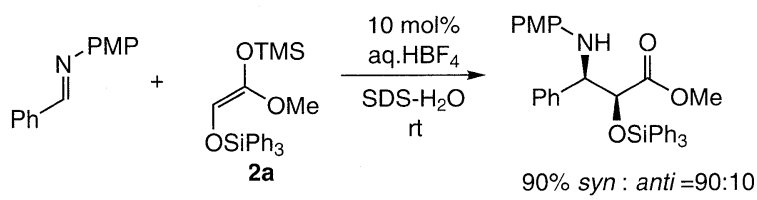

Scheme 7. Anti-selective Mannich-type reaction

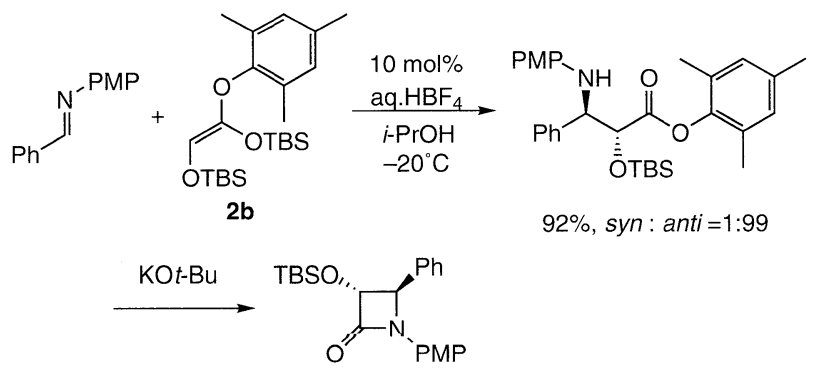

Direct Mannich reaction was successful in aqueous media. HCl-catalyzed Mannich-type reaction exhibited high anti-selectivity when cyclohexanone derivatives were employed as a nucleophile in water in the presence of SDS (Scheme 8). ${ }^{13}$

Scheme 8. Anti-selective Mannich reaction

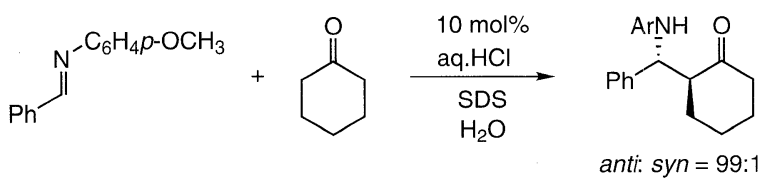

\subsection{Brønsted Acid-catalyzed Aza Diels-Alder Reaction in Aqueous Media}

Hetero Diels-Alder reaction of Danishefsky's diene with imine is a useful method for the preparation of dihydropyridone derivatives. $\mathrm{HBF}_{4}$ turned out to be quite effective as a catalyst for the aza Diels-Alder reaction in aqueous media. On treatment of Danishefsky's diene with aldimine in aqueous $\mathrm{HBF}_{4}(10 \mathrm{~mol} \%)$, pyrrolidinone derivatives were obtained in high yields. ${ }^{14}$ Three-component aza Diels-Alder reaction was successfully achieved by means of the $\mathrm{HBF}_{4}$ catalyst (Scheme 9).

Scheme 9. Three-component aza Diels-Alder reaction

\begin{tabular}{|c|c|c|c|c|c|}
\hline $\mathrm{RCHO}$ & $+\mathrm{Pr}$ & $\mathrm{JH}_{2}+$ & & $\begin{array}{l}10 \mathrm{~mol} \% \\
\text { aq. } \mathrm{HBF}_{4} \\
\longrightarrow\end{array}$ & \\
\hline $\mathrm{R}$ & $\mathrm{Ph}$ & $p-\mathrm{CH}_{3} \mathrm{C}_{6} \mathrm{H}_{4}$ & $c-\mathrm{C}_{6} \mathrm{H}_{11}$ & $\mathrm{PhCH}_{2} \mathrm{CH}_{2}$ & $\left(\mathrm{CH}_{3}\right)_{2} \mathrm{CH}$ \\
\hline Yield & $95 \%$ & $79 \%$ & $80 \%$ & $75 \%$ & $77 \%$ \\
\hline
\end{tabular}

Three-component aza Diels-Alder reaction also proceeded in water in the presence of SDS as a surfactant to give the cycloadducts in good yields (Scheme 10).

Scheme 10. Three-component aza Diels-Alder reaction in water

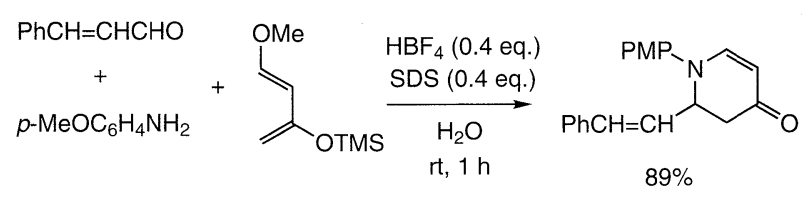

\section{Other Brønsted Acid Catalyzed Reactions}

Addition of dialkyl phosphite to imine constitutes an important method for the preparation of $\alpha$-amino phosphonates, which are isoesters of $\alpha$-amino acid. Brønsted acidcatalyzed three-component hydrophosphonylation of imine with diethyl phosphite also proceeded smoothly under solvent-free conditions to furnish $\alpha$-amino phosphonate in high yields (Scheme 11). ${ }^{15}$

Scheme 11. Three-component hydrophosphonylation

\begin{tabular}{|c|c|c|c|c|}
\hline \multicolumn{2}{|c|}{$\mathrm{RCHO}$} & $\mathrm{NH}_{2}$ & $\underset{\text { No solvent }}{\stackrel{(25 \mathrm{~mol} \%)}{\mathrm{CF}_{3} \mathrm{CO}_{2} \mathrm{H}}}$ & $\overbrace{\substack{11 \\
O}}^{A r N H}$ \\
\hline $\mathrm{R}$ & $\mathrm{Ph}$ & $p-\mathrm{ClC}_{6} \mathrm{H}_{4}$ & $p-\mathrm{NO}_{2} \mathrm{C}_{6} \mathrm{H}_{4}$ & $p-\mathrm{CH}_{3} \mathrm{OC}_{6} \mathrm{H}_{4}$ \\
\hline Yield & $96 \%$ & $95 \%$ & $100 \%$ & $100 \%$ \\
\hline & $\mathrm{hCH}=\mathrm{CH}$ & 2-Furyl & 2-Thienyl & $t-\mathrm{Bu}$ \\
\hline & $88 \%$ & $88 \%$ & $81 \%$ & $98 \%$ \\
\hline
\end{tabular}

Aza Diels-Alder reaction of $N$-aryl imines with silyl enol ethers was catalyzed by trifluoromethanesulfonic acid to give a mixture of tetrahydroquinoline and quinoline derivatives in good yields. Subsequent treatment with $\mathrm{Mn}(\mathrm{OAc})_{3}$ gave 2,4aryl-substituted quinolines in high yields (Scheme 12). ${ }^{16}$

\section{Chiral Brønsted Acid-catalyzed Reactions}

The development of catalytic asymmetric reactions with simple experimental procedures has been a rapidly growing area in synthetic organic chemistry over the past few years. Because we have found that Brønsted acid efficiently catalyzed carbon-carbon bond forming reactions, we next aimed to develop a chiral Brønsted acid catalyst. In order to design a chiral Brønsted acid, we took the following 3 points into account. 
Scheme 12. Aza Diels-Alder reaction
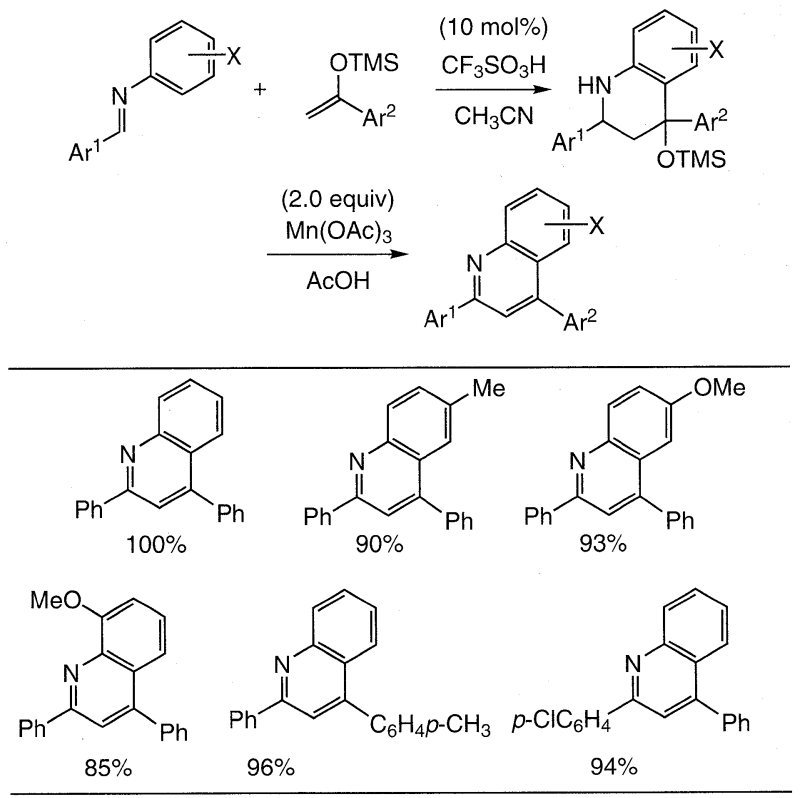

(1) cyclic structure for attaining high asymmetric induction.

(2) suitable acid strength for the reaction to proceed.

(3) use of readily available chiral source.

$(R)$-BINOL was selected as a chiral source. With respect to the acidity, pKa of $(\mathrm{EtO})_{2} \mathrm{P}(\mathrm{O}) \mathrm{OH}$ is 1.3 , which is close to that of $\mathrm{HBF}_{4}(-0.44)$. So we synthesized a cyclic phosphoric acid diester 1a. The acid 1a has been already utilized as a chiral resolving agent, ${ }^{17}$ and its lanthanide salt was used as a chiral catalyst, ${ }^{18}$ but 1a itself had not been used as a chiral catalyst so far.

Recently, it has been established that small organic molecules work as a highly efficient catalyst, in addition to metal complexes and biocatalysts. As a consequence, organocatalysis is gaining importance in asymmetric synthesis. ${ }^{19}$ Among the organocatalysts, hydrogen turned out to be effective as electrophilic activator of carbonyl compounds; Jacobsen reported thiourea is a good catalyst for the addition reaction to imines. ${ }^{20}$ Rawal reported an aza Diels-Alder reaction catalyzed by TADDOL derivative. ${ }^{21,22}$ But a strong chiral Brønsted acid had not been employed as a chiral catalyst so far.

\subsection{Mannich-type Reaction ${ }^{23}$}

In the first place, we examined the Mannich-type reaction ${ }^{24,25}$ of an aldimine with a ketene silyl acetal by means of $30 \mathrm{~mol} \%$ of $1 \mathrm{a}$ (Table 2 ). The corresponding $\beta$ amino acid ester was obtained as a racemate. Gratifyingly, introduction of aryl groups onto the 3,3'-position of binaphthyl rings had beneficial effect on the enantioselectivity; use of $\mathbf{1 b}$ as a catalyst improved the ee value to $27 \%$ (entry 2 ). The screening of 3,3'-substituents revealed that an electrondeficient aryl group showed higher catalytic activity both on the reaction rate and the enantioselectivity. Among the phosphoric acids examined, 1c, bearing a $p$-nitrophenyl group, turned out to be the most effective and the corresponding $\beta$ amino acid ester was obtained in $87 \%$ ee in 4 hours (entry 3 ). The absolute stereochemistry was determined by chiral HPLC analysis by comparison of the retention time with that found in the literature. ${ }^{24 c}$
Table 2. Effect of 3,3'-substituents
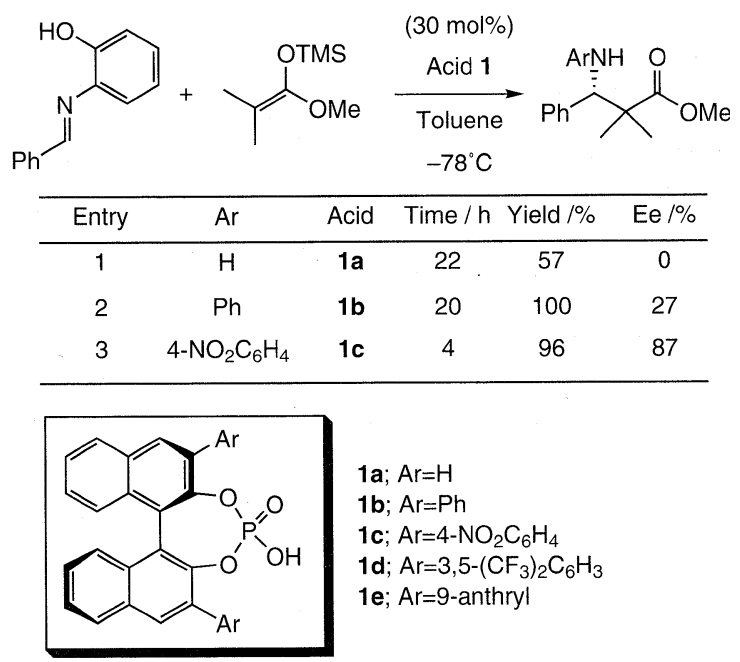

$1 \mathbf{a} ; \mathrm{Ar}=\mathrm{H}$

1b; $\mathrm{Ar}=\mathrm{Ph}$

1c; $\mathrm{Ar}=4-\mathrm{NO}_{2} \mathrm{C}_{6} \mathrm{H}_{4}$

1d; $\mathrm{Ar}=3,5-\left(\mathrm{CF}_{3}\right)_{2} \mathrm{C}_{6} \mathrm{H}_{3}$

1e; $\mathrm{Ar}=9$-anthryl

By further optimization of the reaction conditions, we found that use of aromatic solvents led to high enantioselectivity, whereas protic solvents such as ethanol gave racemates. The substrate scope is shown in Table 3., $\alpha$-Substituted- $\beta$ amino acid esters were obtained with high syn selectivity and the syn isomers exhibited excellent enantioselectivity. The ketene silyl acetal derived from ethyl propionate furnished the corresponding ester in $96 \%$ ee. Substituted aromatic, heteroaromatic, and $\alpha, \beta$-unsaturated aldimines also gave the corresponding adducts with high enantioselectivities.

Table 3. Results of the Mannich-type reaction catalyzed by $\mathbf{1 c}$

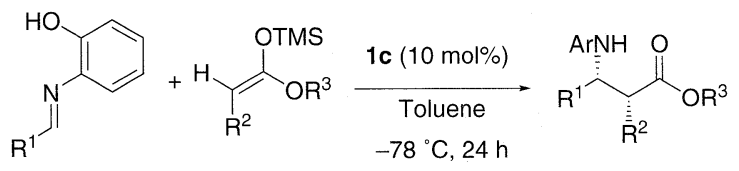

\begin{tabular}{ccccccc}
\hline Entry & $\mathrm{R}^{1}$ & $\mathrm{R}^{2}$ & $\mathrm{R}^{3}$ & Yield/\% & syn/anti & Ee/\% \\
\hline 1 & $\mathrm{Ph}$ & $\mathrm{Me}$ & $\mathrm{Et}$ & 100 & $87: 13$ & 96 \\
2 & $p$-MeOC $6 \mathrm{H}_{4}$ & $\mathrm{Me}$ & $\mathrm{Et}$ & 100 & $92: 8$ & 88 \\
3 & 2 -Thienyl & $\mathrm{Me}$ & $\mathrm{Et}$ & 85 & $94: 6$ & 88 \\
4 & $\mathrm{PhCH}=\mathrm{CH}$ & $\mathrm{Me}$ & $\mathrm{Et}$ & 91 & $95: 5$ & 90 \\
5 & $\mathrm{Ph}$ & $\mathrm{PhCH}_{2}$ & $\mathrm{Et}$ & 100 & $93: 7$ & 91 \\
6 & $\mathrm{PhCH}=\mathrm{CH}$ & $\mathrm{PhCH}_{2}$ & $\mathrm{Et}$ & 65 & $95: 5$ & 90 \\
7 & $\mathrm{Ph}$ & $\mathrm{Ph}_{3} \mathrm{SiO}$ & $\mathrm{Me}$ & 79 & $100: 0$ & 91 \\
\hline
\end{tabular}

${ }^{a}$ Ee value of syn isomer.

After publication of our work, Terada and co-workers independently reported similar phosphoric acid-catalyzed asymmetric reactions. ${ }^{26}$

\subsection{Preparation of Bronsted Acid}

The chiral catalysts 1 were prepared starting from $(R)$ BINOL by way of the known bisboronic acid 3 (Scheme 13). ${ }^{27}$ An aryl group was introduced into the 3,3'-position by Suzuki coupling and methyl ethers were cleaved by $\mathrm{BBr}_{3}$. Subsequent treatment of the BINOL derivative 4 with $\mathrm{POCl}_{3}$ followed by $\mathrm{HCl}$ gave cyclic phosphoric acids $\mathbf{1}$ in good to high yields. 
Scheme 13. Preparation of the catalyst<smiles>COc1ccc2ccccc2c1-c1c(OC)ccc2ccccc12</smiles>
1) $n$-BuLi
2MEDA, $\mathrm{Et}_{2} \mathrm{O}$ $\frac{\text { 1) } \mathrm{ArX}, \operatorname{Pd}(0)}{\text { 2) } \mathrm{BBr}_{3}}$<smiles>Oc1c(Br)cc2ccccc2c1-c1c(O)c(Br)cc2ccccc12</smiles>

$82 \%\left(\mathrm{Ar}=4-\left(\mathrm{NO}_{2}\right) \mathrm{C}_{6} \mathrm{H}_{4}\right)$

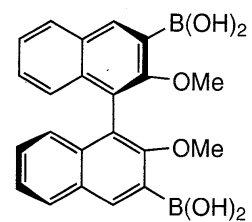

3; $66 \%$
$83 \%\left(\mathrm{Ar}=4-\left(\mathrm{NO}_{2}\right) \mathrm{C}_{6} \mathrm{H}_{4}\right)$

$28,29,30$

4.3 Hydrophosphonylation Reaction ${ }^{28,29,30}$

Enantioselective addition of dialkylphosphite to imine also proceeded smoothly by means of the chiral Brønsted acid catalyst. In the hydrophosphonylation reaction, Brønsted acid 1d, bearing a 3,5-bis(trifluoromethyl)phenyl group on the 3,3'-position, turned out to be the most effective. For the $N$-substituents of imines, the $p$-methoxyphenyl group gave the highest enantioselectivity and the $N$-o-hydroxyphenyl group exhibited low enantioselectivity. The results of the hydrophosphonylation reaction catalyzed by $10 \mathrm{~mol} \%$ of 1d is shown in Table 4. Aldimine derived from cinnamaldehyde derivatives, in particular, exhibited good to high enantioselectivities.

Table 4. Results of the hydrophosphonylation catalyzed by $\mathbf{1 d}$

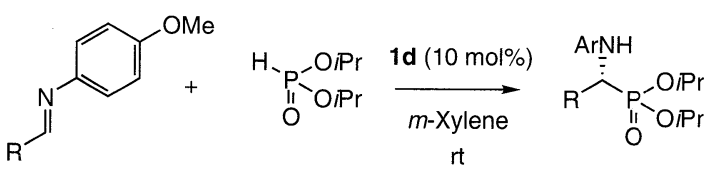

\begin{tabular}{cccc}
\hline Entry & $\mathrm{R}$ & Yield $/ \%$ & $\mathrm{Ee} / \%$ \\
\hline 1 & $o-\mathrm{NO}_{2} \mathrm{C}_{6} \mathrm{H}_{4}$ & 72 & 77 \\
2 & $\mathrm{PhCH}=\mathrm{CH}$ & 92 & 84 \\
3 & $o-\mathrm{ClC}_{6} \mathrm{H}_{4} \mathrm{CH}=\mathrm{CH}$ & 82 & 87 \\
4 & $o-\mathrm{NO}_{2} \mathrm{C}_{6} \mathrm{H}_{4} \mathrm{CH}=\mathrm{CH}$ & 92 & 88 \\
5 & $o-\mathrm{CF}_{3} \mathrm{C}_{6} \mathrm{H}_{4} \mathrm{CH}=\mathrm{CH}$ & 86 & 90
\end{tabular}

\subsection{Aza Diels-Alder Reaction ${ }^{31}$}

Aza Diels-Alder reaction is a useful reaction for the preparation of piperidine derivatives. On treatment of aldimine with Brassard's diene in the presence of phosphoric acid bearing a 9-anthryl group on the 3,3'-position followed by acid treatment, $\alpha, \beta$-unsaturated $\delta$-lactams were obtained with high enantioselectivity (Scheme 14). The present reaction is the first example of the enantioselective aza Diels-

Scheme 14. Results of the aza Diels-Alder reaction

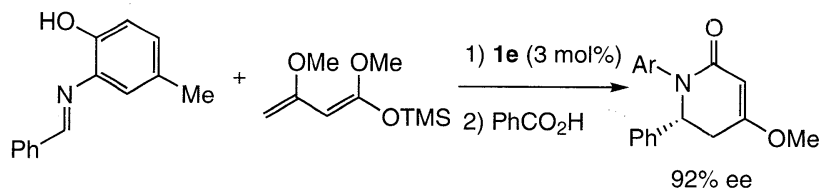

Alder reaction of Brassard's diene with imines as far as we know.

\subsection{Mannich-type Reaction by Means of Brønsted Acid} Derived from TADDOL ${ }^{32}$

It was found that a chiral cyclic phosphoric acid diester derived from $(R)$-BINOL exhibited excellent catalytic activity. In order to survey the steric and electronic factors of the binaphthyl moiety, we designed cyclic phosphoric acid $\mathbf{5}$, bearing a TADDOL scaffold.

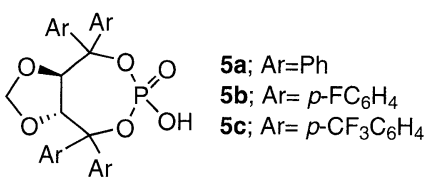

Figure 2. Chiral Brønsted acid bearing TADDOL scaffold.

The catalysts 5 were prepared starting from methylene protected (+)-diethyl tartrate through Grignard addition followed by phosphorylation (Scheme 15). Direct transformation of TADDOL derivative $\mathbf{6}$ to cyclic phosphate 5 by use of $\mathrm{POCl}_{3}$, which was effective for the preparation of chiral phosphate 1 bearing a BINOL scaffold, proved to be unsuccessful. Therefore, an alternative synthetic route was devised by treatment of the diol 6 with $\mathrm{PCl}_{3}$ and subsequent oxidation of dialkyl phosphite 7 by $\mathrm{I}_{2}$, affording dialkyl phosphate $\mathbf{5}$ in good yields.

Scheme 15. Preparation of Brønsted acid bearing TADDOL scaffold

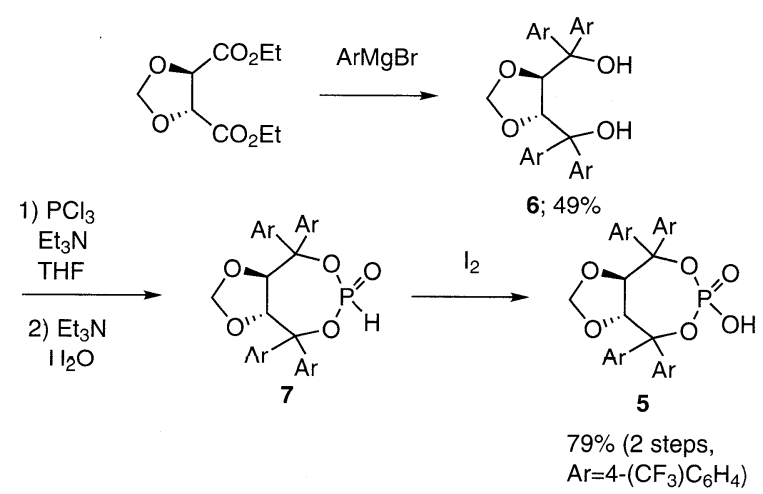

The catalytic activity of $\mathbf{5}$ was highly dependent on the aryl groups as shown in Table 5; although Mannich-type reaction did not proceed by use of $\mathbf{5 a}(\mathrm{Ar}=\mathrm{Ph})$, the corresponding product was obtained in excellent yield and with

Table 5. Effects of aryl substituent of $\mathbf{5}$ on the Mannich-type reaction

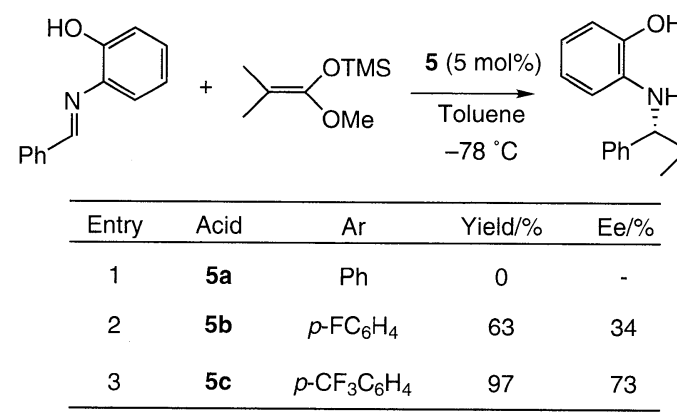


high enantioselectivity by means of $\mathbf{5 c}\left(\mathrm{Ar}=p-\mathrm{CF}_{3} \mathrm{C}_{6} \mathrm{H}_{4}\right)$.

A range of aldimines were found to be good substrates and corresponding $\beta$-amino acid esters were obtained with good to high enantioselectivities by use of $5 \mathrm{~mol} \%$ of $\mathbf{5 c}$ (Table 6).

Table 6. Mannich-type reaction catalyzed by $\mathbf{5 c}$

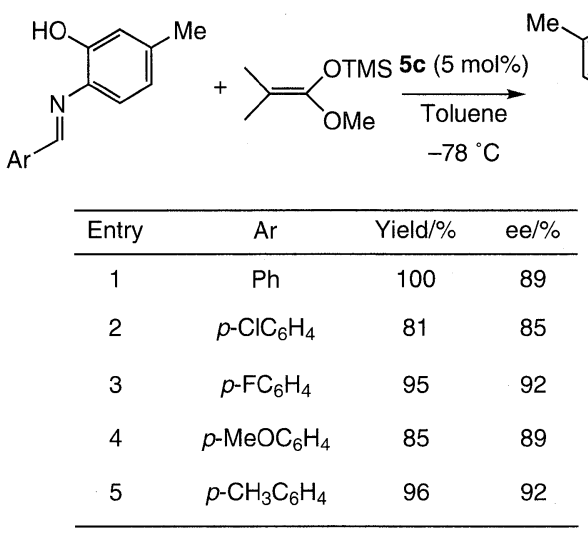

\subsection{Reaction Mechanism}

Next, we speculated the reason why acid 1c exhibited excellent catalytic activity in the Mannich-type reaction. Use of aldimines derived from o-hydroxyaniline is required for attaining high enantioselectivity. We would like to propose a 9-membered cyclic transition state (Figure 3), wherein phosphoryl oxygen forms hydrogen bonding with the imine $\mathrm{OH}$ moiety and a nucleophile attacks the re-face of the imine preferentially. Quantum chemical calculation of the complex of the phosphoric acid 1c and an imine elucidated that the 9membered ring structure is a local minimum. ${ }^{33}$

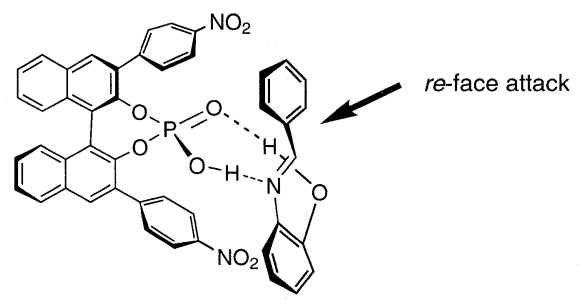

Figure 3. Plausible transition state of the Mannich-type reaction.

In contrast, for the hydrophosphonylation reaction, we would like to propose the following transition state (Figure 4 ), wherein phosphite plays 2 roles: (1) the phosphoric acid hydrogen activates the imine as a Brønsted acid, (2) phosphoryl oxygen activates the nucleophile by coordinating with the hydrogen of the phosphite as a Brønsted base, thereby promoting re facial attack to the imine and increasing the enan-

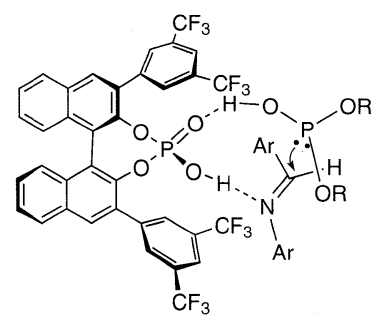

Figure 4. Plausible transition state of the hydrophosphonylation reaction. tioselectivity by the proximity effect.

We would like to propose that phosphoric acid $\mathbf{1}$ acts as a bifunctional chiral Brønsted acid34 bearing both Brønsted acidic and Brønsted basic sites (Figure 5).

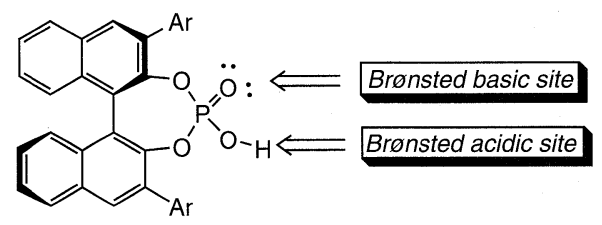

Figure 5. Concept of the bifunctional chiral Brønsted catalyst.

\section{Conclusion}

We have demonstrated the potential of Brønsted acid, not only as the catalyst in aqueous reaction but also as a chiral catalyst in the nucleophilic and cycloaddition reaction to imines. When we started the project on Brønsted acid-catalyzed reactions in 1998, I could not dream of attaining excellent enantioselectivity by use of chiral Brønsted acid. I believe even without a metal catalyst, numerous kinds of asymmetric reactions will be realized by developing more efficient chiral catalysts in the near future.

\section{Acknowledgment}

We are very grateful to our excellent co-workers, Dr. Jun Takaya, Mr. Hisao Morita, Mr. Youichi Saitoh, Mr. Yukio Tamura, Ms. Saeko Nakashima, Mr. Koji Yokota, and Ms. Machiko Sanada for their devoted efforts and hard work. These studies were supported in part by a Grant-in-Aid for Scientific Research from the Ministry of Education, Science, Sports and Culture of Japan. J. I. thanks the JSPS Research Fellowships for Young Scientists.

\section{References}

1) Santelli, M.; Pons, J.-M. Lewis acids and Selectivity in Organic Synthesis, CRC Press, New York, 1996.

2) Jacobsen, E. N.; Pfaltz, A.; Yamamoto, H. Eds. Comprehensive Asymmetric Synthesis, Vol. I, II, III, Springer, Berlin, 1999. (b) Tye, H.; Comina, P. J. J. Chem. Soc., Perkin Trans. I 2001, 1729.

3) For selected examples of Brønsted acid-catalyzed carbon-carbon bond formations, see; (a) Park, J.-Y.; Kadota, I.; Yamamoto, Y. J. Org. Chem. 1999, 64, 4901. (b) Ishihara, K.; Hasegawa, A.; Yamamoto, H. Angew. Chem., Int. Ed. 2001, 40, 4077. (c) Zhang, L.; Kozmin, S. A. J. Am. Chem. Soc. 2004, 126,10204

4) For reviews on organic reactions in aqueous media, see; (a) $\mathrm{Li}$, C.-J. Chem. Rev. 1993, 93, 2023. (b) Li, C.-J.; Chan, T.-H. Organic Reactions in Aqueous Media, John Wiley, New York, 1997. (c) Lubineau, A.; Augé, J.; Queneau, Y. Synthesis, 1994, 741. (d) Li, C.-J. Tetrahedron 1996, 52, 5643. (e) Grieco, P. Ed. Organic Reactions in Water, Blackie Academic \& Professional: London, 1998. (f) Modern Solvents In Organic Synthesis (Topics In Current Chemistry, 206) Knochel, P.; Houk, K. N.; Kessler, H. Eds. Springer Verlag, Berlin, 1999. (g) Lindstrom, U. M. Chem. Rev. 2002, 102, 2751.

5) Akiyama, T.; Iwai, J. Synlett 1998, 273.

6) Kobayashi, S.; Nagayama, S. J. Org. Chem. 1997, 62, 232. Kobayashi, S.; Nagayama, S. J. Am. Chem. Soc. 1997, 119 , 10049.

7) Nakamura, H.; Iwama, H.; Yamamoto, Y. J. Am. Chem. Soc. 1996, 118,6641 .

8) Akiyama, T.; Takaya, J.; Kagoshima, H. Chem. Lett. 1999, 947.

9) Cotton, F. A.; Wilkinson, G. Advanced Inorganic Chemistry, 5th Ed. John Wiley \& Sons, New York 1988, p 174.

10) Akiyama, T.; Takaya, J.; Kagoshima, H. Synlett 1999, 1045.

11) Akiyama, T.; Takaya, J.; Kagoshima, H. Synlett 1999, 1426. Please see also, Manabe, K.; Mori, Y.; Kobayashi, S. Synlet 
1999, 1401

12) Akiyama, T.; Takaya, J.; Kagoshima, H. Tetrahedron Lett. 2001 $42,4025$.

13) Akiyama, T.; Matsuda, K.; Fuchibe, K. Synlett 2005, 322. Please see also, Manabe, K.; Kobayashi, S. Org. Lett. 1999, 1 , 1965. Manabe, K.; Mori, Y.; Kobayashi, S. Tetrahedron 2001 57, 2537. Wu, Y.-S.; Cai, J.; Hu, Z.-Y.; Lin, G.-X. Tetrahedron Lett. 2004, 45, 8949.

14) Akiyama, T.; Takaya, J.; Kagoshima, H. Tetrahedron Lett. 1999 40, 7831 .

15) Akiyama, T.; Sanada, M.; Fuchibe, K. Synlett 2003, 1463.

16) Akiyama, T.; Nakashima, S.; Yokota, K.; Fuchibe, K. Chem. Lett. 2004, 33, 922.

17) Wilen, S. H.; Qi, J. Z. J. Org. Chem. 1991, 56, 487.

18) Inanaga, J.; Sugimoto, Y.; Hanamoto, T. New J. Chem. 1995, 19, 707. Furuno, H.; Hanamoto, T.; Sugimoto, Y.; Inanaga, J. Org. Lett. 2000, 2, 49.

19) For reviews, see; (a) Dalko, P. I.; Moisan, L. Angew. Chem., Int. Ed. 2001, 40, 3726. (b) Dalko, P. I.; Moisan, L. Angew. Chem. Int. Ed. 2004, 43, 5138. (c) Houk, K. N.; List, B. Eds. special issue on organocatalysis, Acc. Chem. Res. 2004, 37, 487. (d) List, B.; Bolm, C. Eds. special issue on organocatalysis, $A d v$. Synth. Cat. 2004, 346, 1021. (e) Berkessel, A.; Gröger, H. Eds Asymmetric Organocatalysis, Wiley-VCH, Weinheim, 2005. (f) Seayad, J.; List, B. Org. Biomol. Chem. 2005, 3, 719.

20) (a) Sigman, M. S.; Vachal, P.; Jacobsen, E. N. Angew. Chem., Int. Ed. 2000, 39, 1279. (b) Wenzel, A. G.; Jacobsen, E. N. J. Am. Chem. Soc. 2002, 124, 12964. (c) Joly, G. D.; Jacobsen, E. N. J. Am. Chem. Soc. 2004, 126, 4102. (d) Fuerst, D. E.; Jacobsen, E. N. J. Am. Chem. Soc. 2005, 127, 8964. See also, (e) Okino, T.; Hoashi, Y.; Takemoto, Y. J. Am. Chem. Soc. 2003 125, 12672. (f) Sohtome, Y.; Tanatani, A.; Hashimoto, Y.; Nagasawa, K. Tetrahedron Lett. 2004, 45, 5589. (g) Okino, $\mathrm{T}$; Nakamura, S.; Furukawa, T.; Takemoto, Y. Org. Lett. 2004, 6 , 625. (h) Hoashi, Y.; Yabuta, T.; Takemoto, Y. Tetrahedron Lett. 2004, 45, 9185 .

21) (a) Huang, Y.; Unni, A. K.; Thadani, A. N.; Rawal, V. H. Nature 2003, 424, 146. (b) Thadani, A. N.; Stankovic, A. R.; Rawal, V. H. Proc. Natl. Acad. Sci. U.S.A. 2004, 101, 5846. (c) Unni, A. K.; Takenaka, N.; Yamamoto, H.; Rawal, V. H. $J$ Am. Chem. Soc. 2005, 127, 1336.

22) For other recent representative papers, see; (a) McDougal, N T.; Schaus, S. E. J. Am. Chem. Soc. 2003, 125, 12094. (b) Nugent, B. M.; Yoder, R. A.; Johnston, J. N. J. Am. Chem. Soc. 2004, 126, 3418. (c) McDougal, N. T.; Trevellini, W. L.; Rodgen, S. A.; Kliman, L. T.; Schaus, S. E. Adv. Synth. Catal. 2004 346, 1231. (d) Pihko, P. M. Angew. Chem., Int. Ed. 2004, 43 2062. (e) Du, H.; Zhao, D.; Ding, K. Chem. Eur. J. 2004, 10 5964. (f) Momiyama, N.; Yamamoto, H. J. Am. Chem. Soc 2005, $127,1080-1081$

23) Akiyama, T.; Itoh, J.; Yokota, K.; Fuchibe, K. Angew. Chem., Int. Ed. 2004, 43, 1566.

24) For selected examples of metal-catalyzed enantioselective Mannich and Mannich-type reactions, see; (a) Ishitani, H.; Ueno, M.; Kobayashi, S. J. Am. Chem. Soc. 1997, 119, 7153. (b) Kobayashi, S.; Ishitani, H.; Ueno, M. J. Am. Chem. Soc. 1998 , 120, 431. (c) Ishitani, H.; Ueno, M.; Kobayashi, S. J. Am. Chem. Soc. 2000, 122, 8180. (d) Kobayashi, S.; Hamada, T. Manabe, K. J. Am. Chem. Soc. 2002, 124, 5640. (e) Hagiwara E.; Fujii, A.; Sodeoka, M. J. Am. Chem. Soc. 1998, 120, 2474. (f) Xue, S.; Yu, S.; Deng, Y.; Wulff, W. D. Angew. Chem., Int. Ed. 2001, 41, 2271. (g) Ferraris, D.; Young, B.; Dudding, T.; Lectka, T. J. Am. Chem. Soc. 1998, 120, 4548. (h) Taggi, A. E.; Hafez, A. M.; Lectka, T. Acc. Chem. Res. 2003, 36, 10. (i) Matsunaga, S.; Kumagai, N.; Harada, S.; Shibasaki, M. J. Am. Chem. Soc. 2003, 125, 4712. (j) Hamada, T.; Manabe, K.; Kobayashi, S. J. Am. Chem. Soc. 2004, 126, 7768. (k) Hamashima, Y.; Sasamoto, N.; Hotta, D.; Somei, H.; Umebayashi, N.; Sodeoka, M. Angew. Chem. Int. Ed. 2005, 44, 1525.

25) For selected examples organo-catalyzed enantioselective Mannich and Mannich-type reactions, see: (a) List, B. J. Am. Chem Soc. 2000, 122, 9336. (b) Hayashi, Y.; Tsuboi, W.; Ashimine, I.; Urushima, T.; Shoji, M.; Sakai, K. Angew. Chem. Int. Ed. 2003 42, 3677. (c) Cordova, A. Acc. Chem. Res. 2004, 37, 102. (d) Chowdari, N. S.; Suri, J. T.; Barbas III, C. F., Org. Lett. 2004, 6, 2507.

26) Uraguchi, D.; Terada, M. J. Am. Chem. Soc. 2004, 126, 5356 Uraguchi, D.; Sorimachi, K.; Terada, M. J. Am. Chem. Soc.
2004, 126, 11804. Uraguchi, D.; Sorimachi, K.; Terada, M. $J$ Am. Chem. Soc. 2005, 127, 9360.

27) Wipf, P.; Jung, J.-K. J. Org. Chem. 2000, 65, 6319.

28) Akiyama, T.; Morita, H.; Itoh, J.; Fuchibe, K. Org. Lett. 2005, $7,2583$.

29) For selected examples of metal-catalyzed hydrophosphonylation reactions, see; (a) Sasai, H.; Arai, S.; Tahara, Y.; Shibasaki, M. J. Org. Chem. 1995, 60, 6656. (b) Groeger, H.; Saida, Y.; Arai, S.; Martens, J.; Sasai, H.; Shibasaki, M. Tetrahedron Lett. 1996, 37, 9291. (c) Groger, H.; Saida, Y.; Sasai, H.; Yamaguchi, K.; Martens, J.; Shibasaki, M. J. Am. Chem. Soc. 1998, 120, 3089. (d) Saida, Y.; Gröger, H.; Maison, W.; Durot, N.; Sasai, H.; Shibasaki, M.; Martens, J. J. Org. Chem. 2000, 65, 4818. (e) Kobayashi, S.; Kiyohara, H.; Nakamura, Y.; Matsubara, R. J. Am. Chem. Soc. 2004, 126, 6558.

30) For organo-catalyed hydrophosphonylation, see; lit. 20c.

31) Akiyama, T.; Itoh, J.; Tamura, Y.; Fuchibe, K. unpublished results.

32) Akiyama, T.; Saitoh, Y.; Morita, H.; Fuchibe, K. Adv. Synth. Catal. 2005, 347, 1523

33) A number of conformers of the complex derived from phosphoric acid 1c and the imine were generated manually and were minimized by Spartan '02 (Wavefuncion, Inc) at the PM3 level.

34) For the bifunctional Lewis acids, see; Shibasaki, M.; Kanai, M.; Funabashi, K. Chem. Commun. 2002, 1989. Kanai, M.; Kato, N.; Ichikawa, E.; Shibasaki, M. Synlett 2005, 1491.

\section{PROFILE}

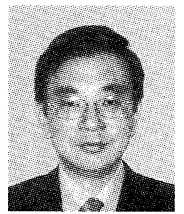

Takahiko Akiyama was born in Kurashiki, Okayama in 1958, and received his Ph.D. in 1985 from the University of Tokyo under the direction of Professor T. Mukaiyama. Immediate thereafter he joined Shionogi Research Laboratories as a research chemist. In 1988 he was appointed Assistant Professor at Ehime University. He joined Professor B. M. Trost's group at Stanford University in 1992. He was appointed Associate Professor at Gakushuin University in 1994. Since 1997 he has been Full Professor at Gakushuin University. His research interest centers around development of novel synthetic methods in particular focused on asymmetric synthesis using organocatalysts as well as metal catalysts.

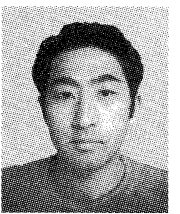

Kohei Fuchibe was born in Fukui in 1974 and received his B.Sc. (1997), M. Sc. (1999), and Ph.D. (2002) degrees from the University of Tokyo. He joined Professor Akiyama's group as Research Associate in 2002. His research interests are in the development of novel organic reactions by use of organometallics.

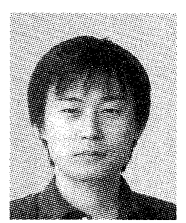

Junji Itoh was born in Chiba in 1978 , graduated from Gakushuin University in 2002, and is now a graduate student of Gakushuin University. In 2005, he was selected as a Research Fellow of the Japan Society for the Promotion of Science. His current research is the development of novel asymmetric reactions by organocatalyst. 